Supporting Information

\title{
Anion effect on structural conformation of tetranuclear cadmium(II) complexes
}

Ruihu Wang, Lei Han, Daqiang Yuan, Yaqiong Gong and Maochun Hong*

State Key Laboratory of Structural Chemistry

Fujian Institute of the Research on the Structure of Matter

Chinese Academy of Sciences, Fuzhou, Fujian, 350002, China

Email: hmc@ms.fjirsm.ac.cn; Fax: +86-591-83714946 
Fig. S1 Soild-state emission spectra of complexes 1-6 and ligand $\mathrm{H}_{2} \mathrm{dpa}$ at room temperature: (a) 1; (b) 2; (c) 3; (d) 4; (e) 5; (f) 6; (g) $\mathrm{H}_{2} \mathrm{dpa}$.

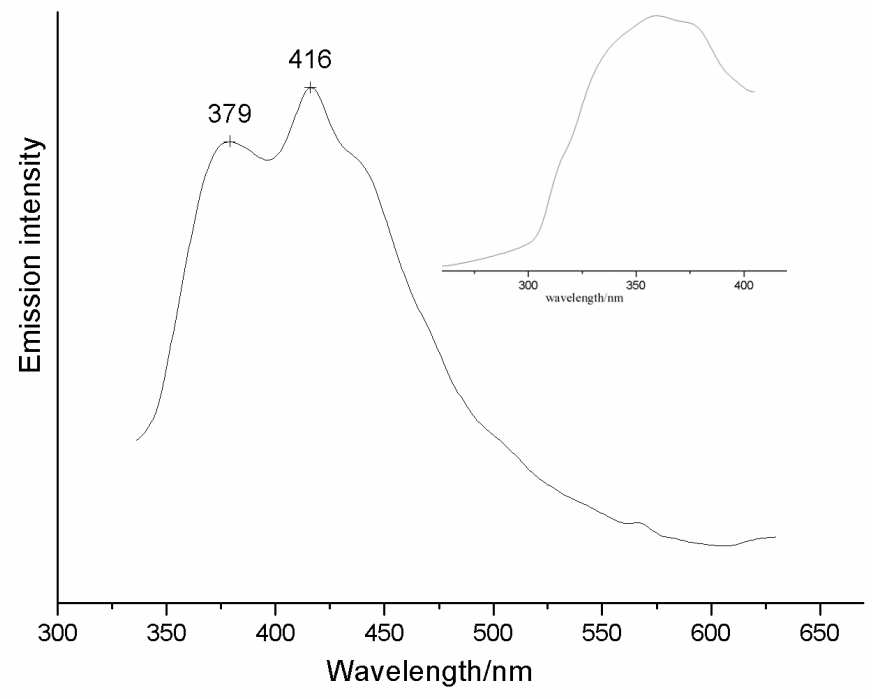

(a)

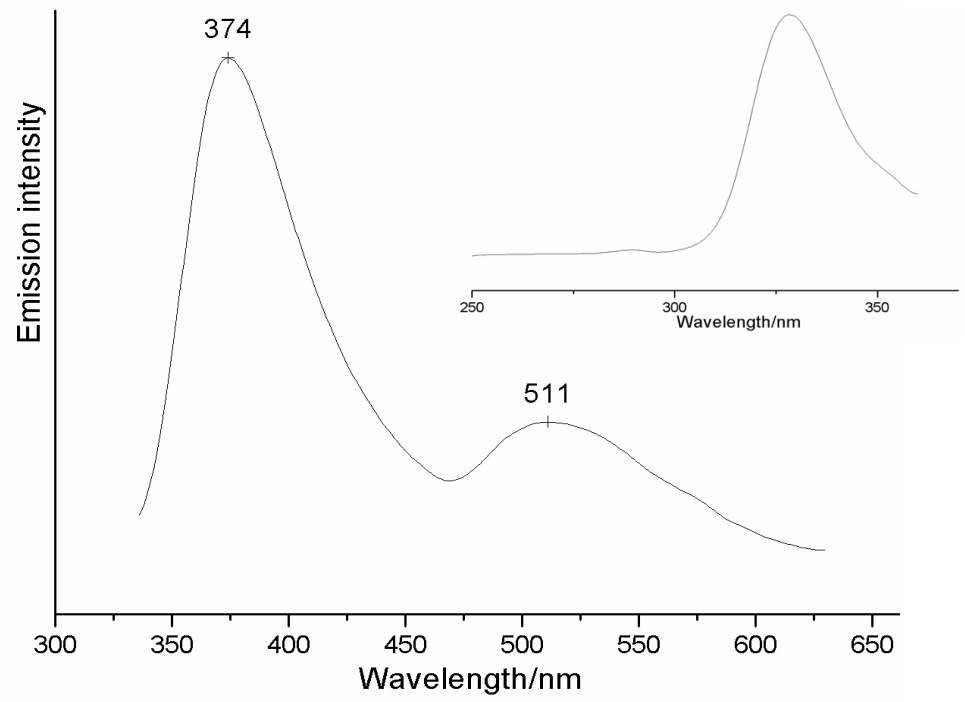


(b)

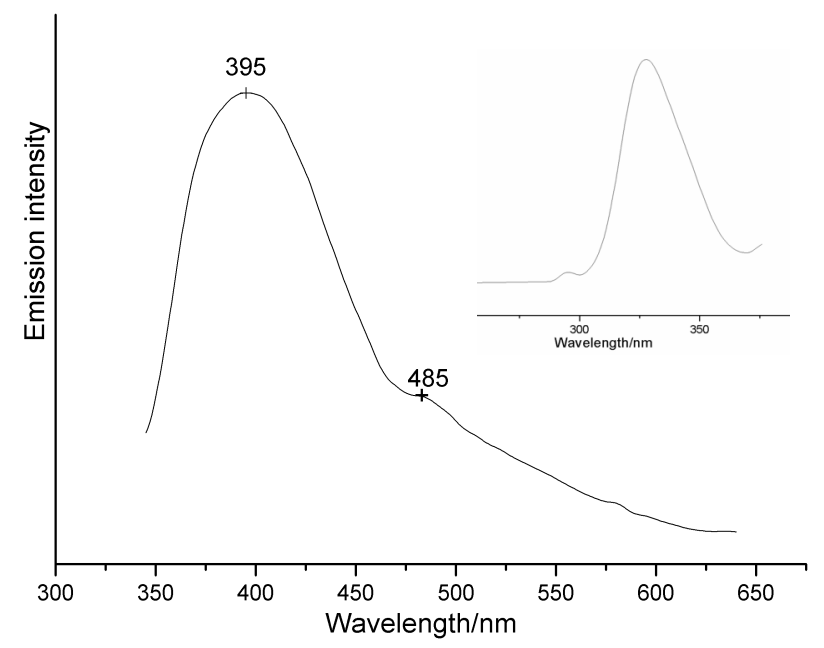

(c)

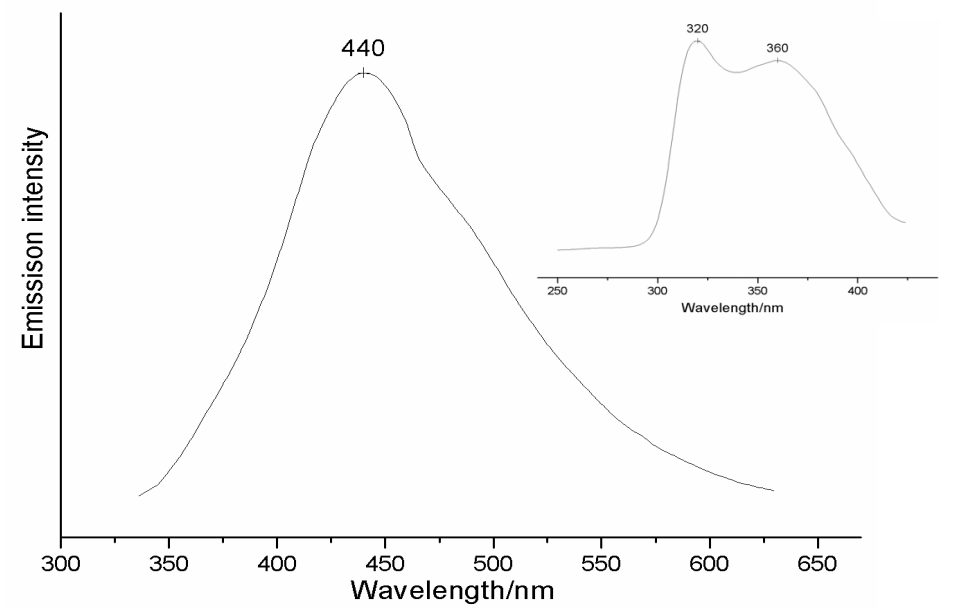

(d) 


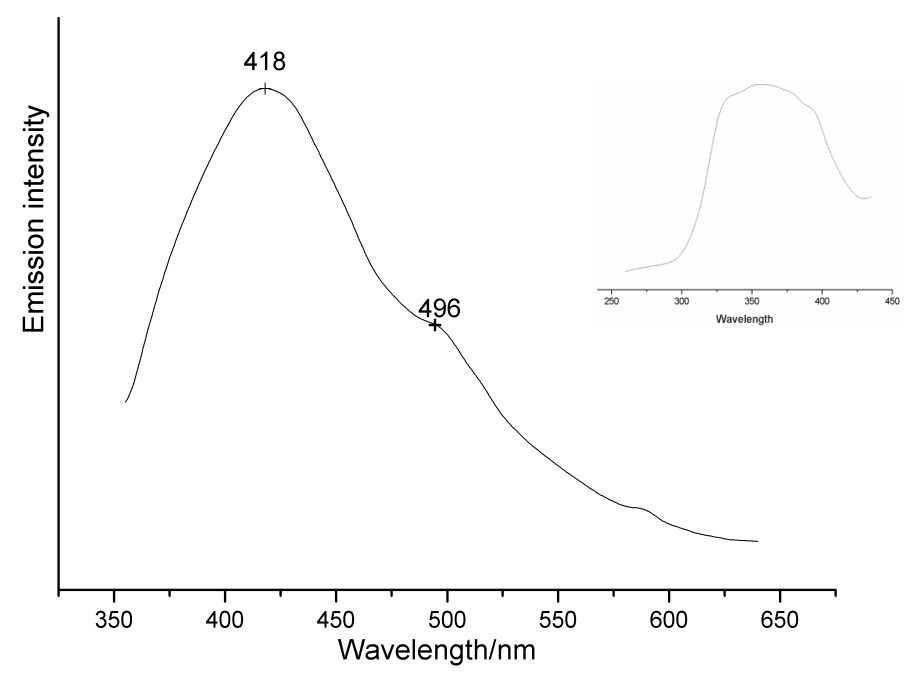

(e)

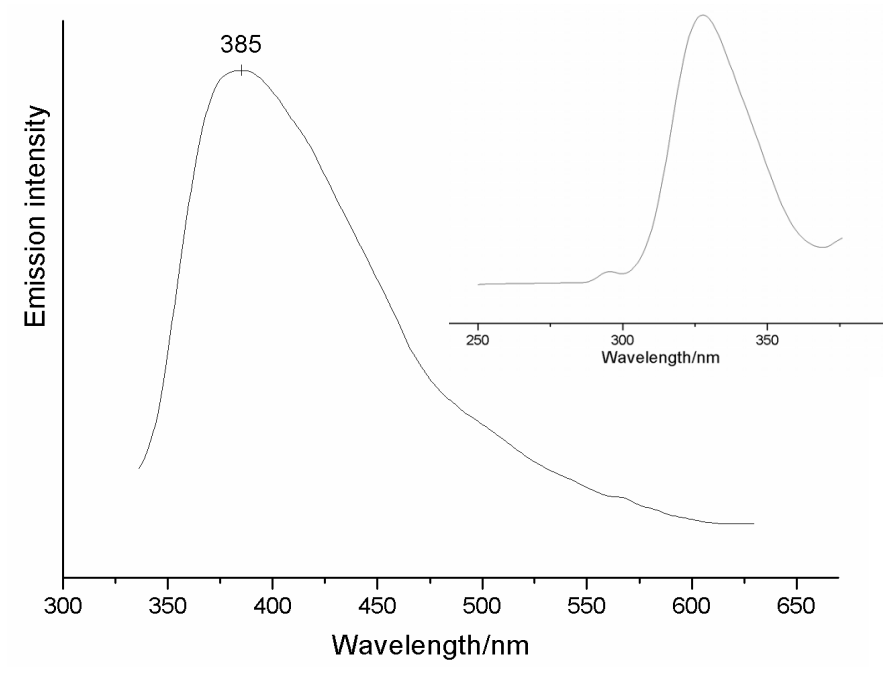

(f) 


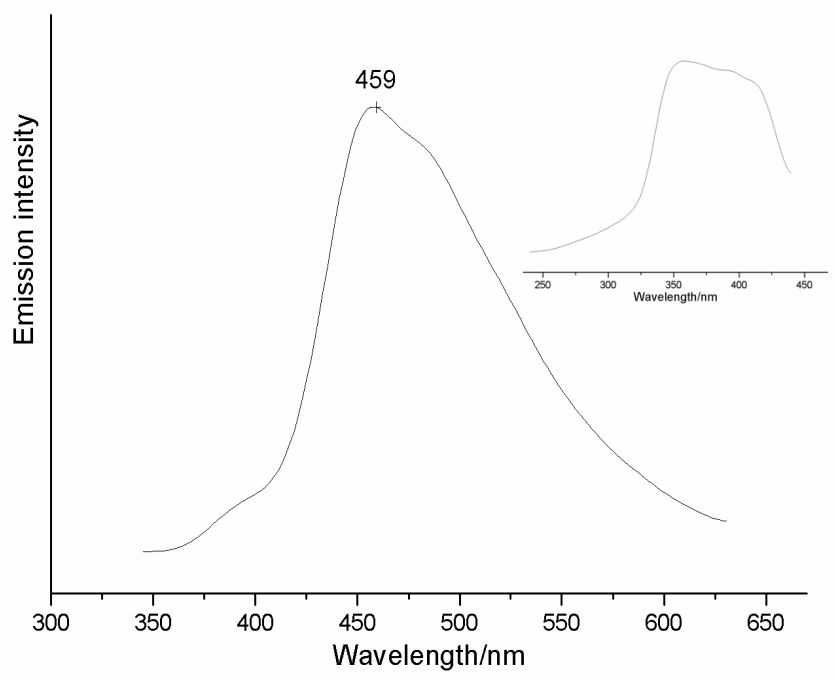

(g) 